de Gruyter Studium

Peter von Polenz

Deutsche Sprachgeschichte I 



\title{
Deutsche Sprachgeschichte
}

vom Spätmittelalter bis zur Gegenwart

\author{
von \\ Peter von Polenz
}

Band I

Einführung · Grundbegriffe ·

14. bis 16. Jahrhundert

\author{
3. Auflage \\ bearbeitet von \\ Claudine Moulin \\ unter Mitarbeit von \\ Maria Backes und Natalia Filatkina
}

De Gruyter 
ISBN 978-3-11-034794-4

e-ISBN (PDF) 978-3-11-049620-8

e-ISBN (EPUB) 978-3-11-049353-5

Library of Congress Control Number: 2020952730

Bibliografische Information der Deutschen Nationalbibliothek.

Die Deutsche Nationalbibliothek verzeichnet diese Publikation in der Deutschen Nationalbibliografie; detaillierte bibliografische Daten sind im Internet über http://dnb.dnb.de abrufbar.

C) 2021 Walter de Gruyter GmbH, Berlin/Boston

Einbandabbildung: Leyenschul. WIe man Künstlich und behend, schreyben unnd lesen soll lernen. Staatsbibliothek zu Berlin - PK, Ng 335, S. 13, URL: http://resolver. staatsbibliothek-berlin.de/SBB0001A34200000013, Public Domain Mark 1.0

Satz: Dörlemann Satz, Lemförde

Druck und buchbinderische Verarbeitung: CPI books GmbH, Leck

www.degruyter.com 